\title{
A DESIGUALDADE DE GÊNERO QUE REFLETE NO ENCARCERAMENTO FEMININO BRASILEIRO
}

\section{GENDER INEQUALITY REFLECTING IN BRAZILIAN FEMALE INCARCERATION}

\author{
Josiane Pantoja Ferreira \\ josianepantoja@hotmail.com \\ Universidade do Estado do Ceará
}

\section{Resumo:}

O presente artigo é fruto da disciplina Desigualdades em Gênero, Geração e Etnia, ministrada no Mestrado Profissional em Planejamento e Políticas Públicas da Universidade Estadual do Ceará UECE. O trabalho faz uma abordagem sobre o crescimento populacional do aprisionamento feminino brasileiro, analisando a situação de preconceito da mulher no mercado de trabalho e mostrando que a mulher presa também sofre com a discriminação. A pesquisa bibliográfica desenvolvida, neste trabalho, tem como base o Levantamento Nacional de Informações Penitenciárias do MJ/DEPEN ${ }^{1}$; a Pesquisa Nacional por Amostra de Domicílios (PNAD), do IBGE (2017), que realizou um estudo sobre o mercado de trabalho. Portanto, o cárcere para mulheres exprime e revela a desigualdade de gênero presente em diferentes espaços sociais.

Palavras-chave: Mulher presa, Mercado de trabalho, discriminação.

\begin{abstract}
:
The present article is the result of the discipline Inequalities in Gender, Generation and Ethnicity, taught in the Professional Master in Planning and Public Policies of the State University of CearáUECE. The work takes an approach on the population growth of Brazilian female imprisonment, analyzing the situation of prejudice of women in the labor market and showing that the woman imprisoned also suffers from discrimination. The bibliographic research developed in this work is based on the National Survey of Penitentiary Information of MJ/DEPEN; The National Household Sample Survey (PNAD), from IBGE (2017), which conducted a study on the labor market. Therefore, the prison for women expresses and reveals the gender inequality present in different social spaces.
\end{abstract}

Key words: Woman arrested, Labor market, discrimination.

\section{INTRODUÇÃO}

\footnotetext{
${ }^{1}$ Ministério da Justiça - MJ e Departamento Penitenciário Nacional - DEPEN
} 
A população feminina no Brasil, segundo o IBGE é superior numericamente a masculina. $\mathrm{Na}$ atualidade as mulheres desempenham inúmeras atividades que perpassam pela economia, politica, intelectualidade, ou seja, por todas as esferas da sociedade, antes reservada somente aos homens. Apesar da crescente participação das mulheres no mundo do trabalho, de modo geral, a desigualdade de gênero ainda persiste.

As disparidades de gênero, são apresentadas em diversos indicadores socioeconômicos, como por exemplo, os dados apresentados pelo Fórum Econômico Mundial, pela Comissão Econômica Para a América Latina e o Caribe - CEPAL, pelos dados da População Economicamente Ativa - PEA, pelos dados do Instituto de Pesquisa Econômica Aplicada - IPEA, pela Pesquisa Mensal de Emprego - PME e outros. Essa pesquisa abordara os dados do Levantamento Nacional de Informações Penitenciárias do MJ/DEPEN e a Pesquisa Nacional por Amostra de Domicílios PNAD, do IBGE (2017).

Portanto, ao examinar os dados do MJ/DEPEN e da PNAD, observa-se que as mulheres, ainda são vítimas de discriminações e preconceitos, tanto na sociedade "livre" como na penitenciária, pois no ambiente carcerário existe uma relação assimétrica entre homens e mulheres, o que ocasiona violações de direito das mulheres privadas de liberdade.

\section{O CRESCIMENTO POPULACIONAL DO APRISIONAMENTO FEMININO BRASILEIRO}

O sistema penitenciário feminino não é tão diferente do masculino quando comparada a situação de infraestrutura, pois no sistema feminino nos deparamos com infraestruturas precárias, sem iluminação, sem ventilação, péssimas condições de higiene, excesso de lotação, dentre outras mazelas, tornando-se um espaço propício ao contágio e proliferação de doenças. Diante deste panorama, uma pessoa que inicia o cumprimento da pena com saúde, provavelmente sairá da penitenciária com a saúde física e/ou mental comprometida. Essa realidade tende a se ampliar cada vez mais, caso não seja viabilizado políticas públicas para esse ambiente (MJ/DEPEN, 2015).

O Brasil apresentava no ano de 2014, segundo o DEPEN, a quinta maior população de mulheres presas no mundo, perdendo apenas para os Estados Unidos, China, Rússia e Tailândia. A população de mulheres encarceradas brasileiras apresenta um crescimento avassalador, em 


\section{A DESIGUALDADE DE GÊNERO QUE REFLETE NO ENCARCERAMENTO \\ FEMININO BRASILEIRO}

contrapartida as políticas públicas e o ambiente prisional não estão preparados para oferecer o mínimo a essas mulheres. Essas, em sua grande maioria, permanecem cumprindo suas penas em lugares inadequados. O Estado, não consegue prover a quantidade necessária de penitenciárias com destinação específica, e elas acabam cumprindo sua sentença em ambiente misto, o que contribui com o desrespeito as individualidades das mulheres em restrição de liberdade, e faz com que elas recebam o mesmo tratamento disponibilizado aos homens. (MJ/DEPEN, 2015)

A prisão, historicamente, é um lugar habitado majoritariamente por homens, porém, é alarmante o crescimento da população feminina nas penitenciárias. O sistema penitenciário brasileiro tem 37.380 mulheres presas. No período de 2000 a 2014 a população feminina aumentou $567,4 \%$, em contrapartida, a média de crescimento masculino, no mesmo período, foi de $220,20 \%$. Isso revela o crescimento descomunal do aprisionamento feminino. (MJ-DEPEN, 2015).

O cometimento de ilícitos por mulheres cresce vertiginosamente, e, por conseguinte, sua presença nas penitenciárias. Como dito, em sua grande maioria não tendo estabelecimento próprio para cumprimento da pena. Os dados levantados pelo INFOPEN revelam que há 1.070 unidades masculinas, o que representa um percentual de $76 \%$. Nas outras destinações há o indicativo de 238 estabelecimentos mistos $17 \%$ e 103 estabelecimentos femininos 7\%, evidenciando, assim, que a grande maioria das mulheres presas está cumprindo pena em estruturas mistas (MJ-DEPEN, 2015).

Esses dados desobedecem a Constituição Federal art 5ㅇ, XLVIII, que preconiza que "a pena será cumprida em estabelecimentos distintos, de acordo com a natureza do delito, a idade e o sexo do apenado", esse direito também é assegurado na Lei de Execuções Penais, Código Penal e outras normativas inclusive internacionais (BRASIL, 1988).

Porém, sua efetivação deixa muito a desejar, pois é obrigação do Estado construir estabelecimento prisional em quantidade adequada a situação de gênero, para que não falte vaga para acomodar a demanda que lhe é imposta. A construção de penitenciárias, voltadas para o público feminino é essencial para a criação de políticas públicas específicas, que respeitem as individualidades desse segmento. 
Portanto, a presença feminina nas penitenciárias ainda é considerada pequena em relação aos homens, e isso não pode ser usado como justificativa para que os direitos das mulheres encarceradas permaneçam sendo negligenciados. De acordo DEPEN, as mulheres presas já representam 6,5\% da população carcerária. Logo, é fundamental que suas especificidades sejam respeitadas no ambiente prisional e na sociedade em geral (MJ-DEPEN, 2015).

\section{A CONDIÇÃO DA MULHER NA SOCIEDADE E NO CÁRCERE}

Ao constatar, o crescimento do aprisionamento feminino, e analisar juntamente com a síntese de indicadores sociais uma análise das condições de vida da população brasileira do IBGE (2017), identifica-se que as mulheres são tratadas de forma desigual tanto na sociedade "livre" como no ambiente prisional, pois as informações da Pesquisa Nacional por Amostra de Domicílios (PNAD) realizou um estudo sobre: O mercado de trabalho, padrão de vida, distribuição de renda, mobilidade ocupacional e educacional. Esta pesquisa mostrou que as mulheres figuram entre os grupos de maior vulnerabilidade, grupo este composto por: pretos ou pardos, jovens e população ocupada menos escolarizada. (IBGE, 2017).

No estudo referente ao nível de desocupados, ou seja, desempregados, a desocupação por cor ou raça, os pretos e pardos representam $62,6 \%$, com relação ao gênero e as mulheres aparecem com o índice de $50,1 \%$. Nesse sentido, as mulheres jovens são as que mais sofrem com a desocupação, uma vez que:

(...) é na categoria mulher de 16 a 29 anos que a taxa de desocupação atingiu o nível mais alto dentre todos os grupos populacionais, com 24,0\%. Tal incremento representou 2,2 milhões de mulheres a mais em 2016 que procuraram e não encontraram ocupação, em relação a 2014. (IBGE, 2017, n.p)

Vale ressaltar, que os Estados que registraram os maiores índices nas taxas de desocupação foram o Amapá e a Bahia, ambos com 15,6\%. É relevante destacar também, que os maiores índices de desocupação por cor ou raça, são das populações preta ou parda, que estão localizadas nos Estados do Amapá, Bahia e Pernambuco e figuram com índices acima de 16,0\%. (IBGE, 2017). 


\section{A DESIGUALDADE DE GÊNERO QUE REFLETE NO ENCARCERAMENTO \\ FEMININO BRASILEIRO}

Segundo o IBGE 2017, o percentual da desocupação do sexo feminino é superior ao masculino em todas as unidades da federação, os Estados que possuem os maiores índices são: Amapá, Amazonas e Bahia com índices acima de 18,0\%. O IBGE, ao analisar a subutilização da força de trabalho revelou também que as mulheres figuram com $25,1 \%$ dos índices de subutilização da força de trabalho, enquanto que para os homens essa taxa é de $17,2 \%$.

Verifica-se, na pesquisa realizada pelo IBGE, que a mulher apesar de sua crescente participação no mundo do trabalho, ainda enfrenta dificuldades para conseguir um emprego. A inserção do público feminino no mercado de trabalho ocorre por diversos fatores, como a necessidade econômica, onde a pessoa se ver obrigada a laborar para contribuir com o orçamento familiar. A falta de acesso da mulher ao mercado de trabalho, pode contribuir com a sua inserção no mundo da criminalidade, segundo Marx (2006, p.15) “Os homens fazem a sua própria história, mas não a fazem segundo a sua livre vontade; não a fazem sob circunstâncias de sua escolha e sim sob aquelas com que se defrontam diretamente, legadas e transmitidas pelo passado".

Nesse sentido, as contingências sociais, como o desemprego, podem influenciar a atitude das pessoas, de acordo com o INFOPEN, os delitos mais praticados por mulheres são os que trazem um proveito econômico imediato, como o tráfico de drogas, roubo e furto, conforme o gráfico a seguir:

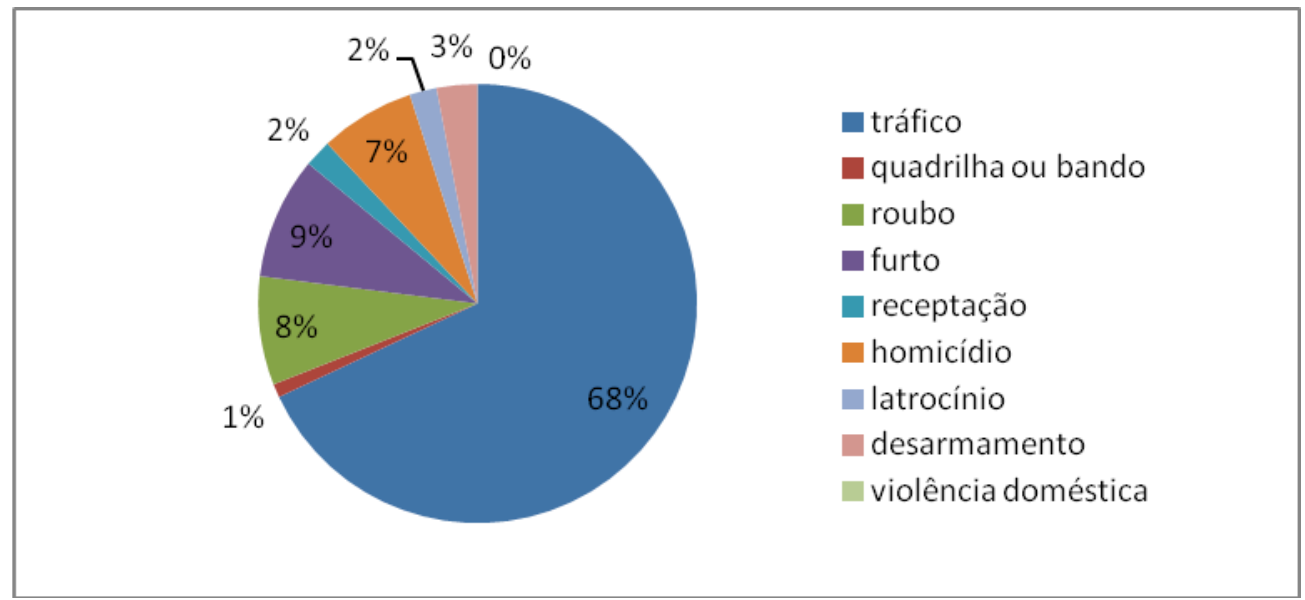

Figura 1 - Crimes praticados pelas mulheres

Fonte: MJ/DEPEN, 2015.

O tráfico de droga desponta com $68 \%$, como o delito que mais leva as mulheres para a prisão, esse índice elevado é devido a diversos fatores, segundo Carvalho e Jesus (2012, p. 178), 
“(...) esse envolvimento se desencadeia a partir da ligação afetiva da mulher com um traficante e que, por uma razão específica, ficou impedido de fazê-lo e permitiu que a mulher ocupasse esta função para complementação da renda familiar".

Nesse viés, Moura (2012, p.132) sinaliza que:

(...) o desemprego estrutural e o estado de absoluta necessidade de meios para prover a sobrevivência pessoal e/ ou da família constituem os maiores responsáveis pela inserção das mulheres no "negócio da droga". Desta forma, o tráfico passa a constituir facilmente a estratégia de sobrevivência. Entendo que refletir a questão do tráfico de drogas, considerando a exclusão social, não significa associar pobreza a criminalidade, mas dar visibilidade ao fato de que os que não pertencem à categoria de excluídos, os verdadeiros donos de tão rentável negócio, ficam intocáveis, sem qualquer sanção penal.

Essas narrativas retratam e representam, que a falta de acesso das mulheres ao mercado de trabalho formal, faz com que as mulheres encontrem no crime uma fonte para a subsistência.

Nesse enfoque, França $(2013$, n.p) relata que as exigências e dificuldades impostas pelo mercado de trabalho acabam por colaborar com a inserção da mulher no mundo do crime, pois:

(...) o tráfico de drogas aparece como uma alternativa viável, pois é capaz de oferecer um retorno financeiro mais rápido às mulheres que em face da baixa escolaridade, não conseguem uma colocação no mercado de trabalho ou quando conseguem, recebem uma remuneração ínfima.

A pesquisa do IBGE (2017), revela que as mulheres que usufruem de sua liberdade encontram dificuldades para acessar e permanecer no mercado de trabalho, situação que se agrava ainda mais para as mulheres encarceradas, pois se antes do aprisionamento a colocação no mercado de trabalho para as mulheres já era precário, essa situação, se torna ainda mais difícil para as mulheres que cumpriram penas em estabelecimentos prisionais, devido ao "(..) estigma que passam a carregar e pela organização social falha e preconceituosa a que foram submetidas." (FRANÇA 2013, n.p)

O ambiente prisional, estigmatiza, oprime e discrimina muito mais as mulheres que os homens, as políticas públicas sociais voltadas para os encarcerados são pensadas e planejadas predominantemente para os homens, deixando de lado as peculiaridades do público feminino, que por inúmeras vezes têm seus direitos e sua dignidade violada. É fundamental, portanto, olhar 


\section{A DESIGUALDADE DE GÊNERO QUE REFLETE NO ENCARCERAMENTO \\ FEMININO BRASILEIRO}

de forma singularizada para o ambiente feminino, a fim de explicitar nas legislações os direitos das mulheres encarceradas (CASTILHO, 2007).

No Brasil, numericamente as mulheres são superiores aos homens, porém, as políticas públicas também refletem o contexto histórico e social da invisibilidade feminina, seja na sociedade "livre" ou no cárcere, nesse sentido, é imprescindível que haja mudanças plausíveis em nosso país, e as políticas públicas que evidencie e respeite a realidade da diversidade de gênero é capaz de contribuir significativamente com a superação da discriminação e violação de direitos tanto na sociedade extramuros como na intramuros.

Cumpre ressaltar, que de acordo com França (2013, n.p), “O cárcere feminino exprime e revela as desigualdades de gênero presente nos diferentes espaços sociais, mas que ganha maior proporção se considerarmos as desigualdades sociais, econômicas e étnico-raciais". Por isso, é fundamental um olhar diferenciado onde as mulheres encarceradas possam sair da invisibilidade e ter seus direitos respeitados. Dessa forma, é necessário promover e incentivar nos presídios a escolarização e a capacitação profissional das mulheres prisioneiras, para que ao sair do cárcere seja possível sua colocação no mercado de trabalho.

A Lei de Execução Penal prevê que a assistência educacional compreenderá a instrução escolar e a formação profissional, da pessoa privada de liberdade, e assegura que o Estado deve fornecer à pessoa privada de liberdade assistência educacional, com a finalidade de prevenir o crime e orientar o retorno à convivência em sociedade. É fundamental a escolarização das mulheres encarceradas, tendo em vista que a maior parte das mulheres presas possui um grau de escolaridade baixíssimo, sendo elucidado no presente gráfico da escolaridade da população prisional brasileira: 


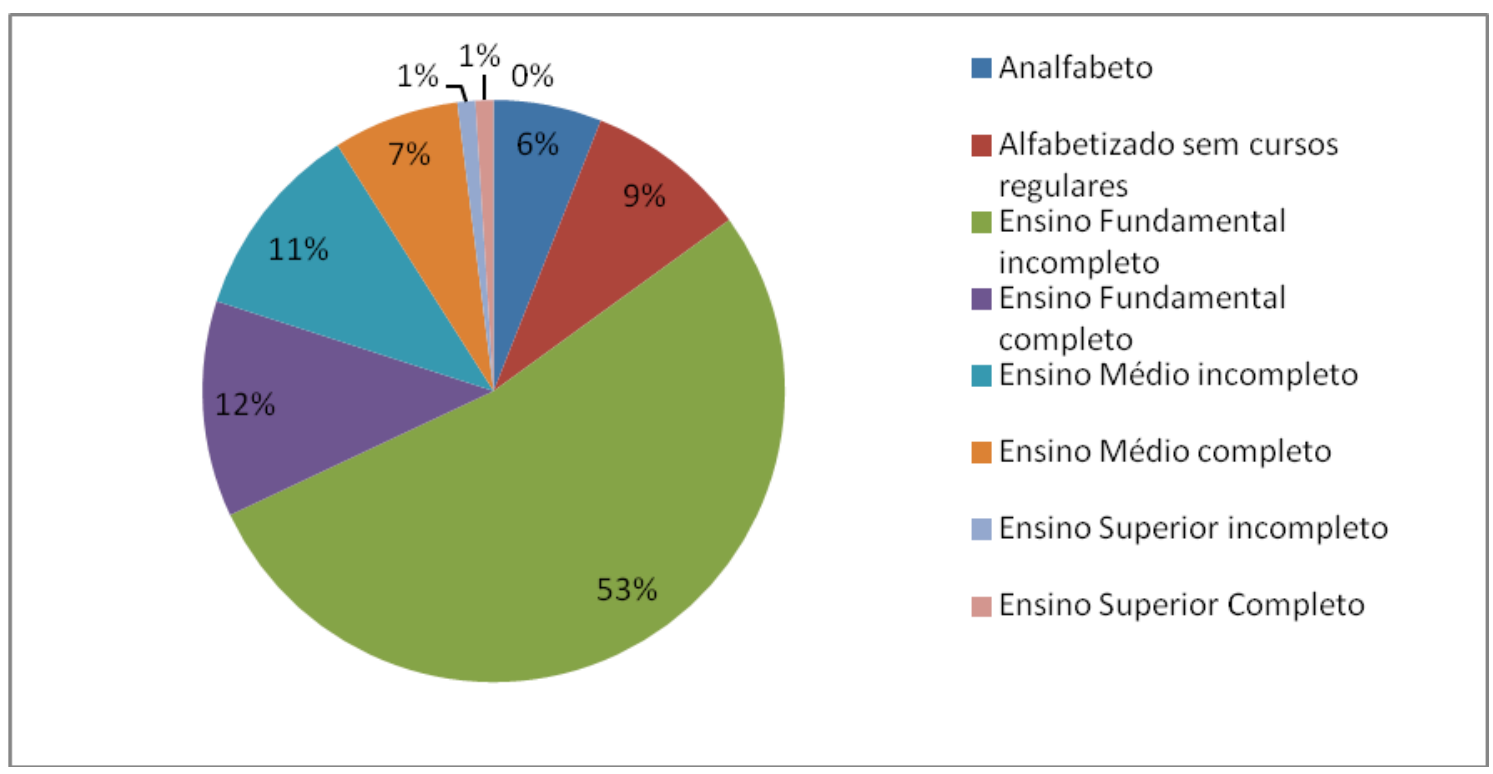

Figura 2 - Escolaridade da população prisional brasileira Fonte: INFOPEN/MJ, 2015.

Conforme os dados $53 \%$ dos detentos brasileiros possuem somente o ensino fundamental incompleto, se somarmos a esse percentual os analfabetos, os alfabetizados sem cursos regulares e os que possuem o ensino fundamental completo chegar-se-á a um percentual de $80 \%$, uma porcentagem um tanto inquietante visto que isso representa um público com nenhuma ou pouca escolarização. "Um dado preocupante se considerarmos que a educação possibilita a melhoria da formação humana e contribui para a ascensão socioeconômica" (OLIVEIRA, 2014, P. 84).

A capacitação profissional é uma das exigências do mercado de trabalho, logo, a oferta de escolarização e cursos de capacitação profissional, no interior dos presídios, são fundamentais para contribuir com o processo de inserção das mulheres encarceradas no mercado de trabalho. Pois, ao receber o alvará de soltura, a luta para acessar o mundo do trabalho não será fácil, tendo em vista que a cada dia está mais acirrada a competição, e quem não tem capacitação e carrega o estigma de ex-presidiária fica mais difícil ter uma oportunidade de emprego (DI PIERRO, 2005).

A condição da mulher na sociedade também se reflete no cárcere, segundo dados do IBGE as mulheres são o grupo da sociedade mais vulnerável, sem acesso ao mercado de trabalho, principalmente as mulheres na faixa etária de 16 a 29 anos, de cor negra e de baixa escolaridade. O perfil da mulher livre, sem oportunidade de emprego, coincide com o perfil das mulheres presas, que cumprem pena nas penitenciárias brasileiras, uma vez que, as mulheres em privação de liberdade, segundo o MJ/DEPEN (2015), são jovens de 18 a 29 anos, representando um 


\section{A DESIGUALDADE DE GÊNERO QUE REFLETE NO ENCARCERAMENTO \\ FEMININO BRASILEIRO}

percentual de $50 \%$, de cor negra $67 \%$, de baixa escolaridade, de baixa renda, possuem filhos, e antes do encarceramento exerciam suas atividades laborais na informalidade, e eram responsáveis pelo sustento da família.

Portanto, para no mínimo amenizar essa realidade, rugosa, áspera e terrificante da desigualdade de gênero, e vislumbrarmos a construção de uma sociedade onde as pessoas e as legislações que regem o Brasil sejam menos rugosas e arestosas; a criação, implementação, fiscalização e avaliação das políticas públicas comprometidas com a realidade social são fundamentais.

\section{CONSIDERAÇÕES FINAIS}

No decorrer do trabalho foi exposto de acordo com as informações do DEPEN que as mulheres presas já representam $6,5 \%$ da população carcerária, a presença feminina nas penitenciárias ainda é considerada pequena em relação aos homens, e isso não pode ser usado para justificar a violação dos direitos das mulheres encarceradas.

As mulheres prisioneiras têm necessidades e peculiaridades que são por sua natureza especifica do gênero feminino, e isso não pode ser negligenciado, pois, a maneira como as mulheres formam suas ligações familiares, bem como se relacionam com o crime ocorrem de forma diferenciada. No entanto, no percorrer da história, observa-se, que o ambiente prisional é preparado para que sua engrenagem funcione para atender aos interesses do público masculino, deixando de lado as peculiaridades do universo feminino.

É fundamental que o Estado tenha um olhar diferenciado para as penitenciárias femininas, a fim de desenvolver políticas públicas para essa população, no sentido de amenizar essa discriminação e explicitar nas legislações os direitos das mulheres encarceradas, bem como estimular a criação de cursos de capacitação profissional que abarque as mulheres em restrição de liberdade, para que ao sair do ambiente penitenciário possam conseguir uma colocação no mercado de trabalho.

A capacitação profissional é uma das exigências do mundo do trabalho, logo a oferta de escolarização e cursos de capacitação profissional no interior dos presídios é fundamental, para cooperar com o processo de inserção das mulheres no mercado de trabalho, pois a luta para 
acessar e permanecer no mercado do trabalho está cada dia mais difícil, e a situação se agrava no caso das mulheres que já passaram pelo cárcere.

Portanto, o ambiente prisional feminino elucida as desigualdades de gênero presente nos diferentes espaços sociais. A partir do estudo a respeito da presença feminina no mercado de trabalho, observa-se que a sociedade ainda relega um papel secundário as mulheres, é isso contribui com a discriminação e violação de direitos, tanto no mundo extramuros e intramuros.

\section{REFERÊNCIAS BIBLIOGRÁFICAS}

BRASIL. Constituição da República Federativa do Brasil. 1988. Brasília: Senado Federal, 2001. 407p.

Lei de Execução Penal. Lei № 7.210 de 11 de julho de 1984. Institui a Lei de Execução Penal. Disponível em: <http://www.planalto.gov.br/ccivil_03/leis/l7210. htm>. Acesso em: 16 Jan. 2018.

. Ministério da Justiça. Departamento Penitenciário Nacional. Levantamento nacional de

informações penitenciarias INFOPEN-junho 2014. Disponível em:<
http://189.28.128.100/dab/docs/portaldab/documentos/relatorio_depen.pdf> Acesso em 08 jan. 2018.

IBGE. Síntese de Indicadores Sociais: Uma análise das condições de vida da população

brasileira, 2017. Não paginado. Disponível em:
https://biblioteca.ibge.gov.br/visualizacao/livros/liv101459.pdf. Acesso em: 12 Jan. 2018.

CARVALHO, Denise; JESUS, Maria Gorete Marques de. Mulheres e o tráfico de drogas: um retrato das ocorrências de flagrante na cidade de são Paulo. Revista do Laboratório de Estudos da Violência da UNESP/Marília, Edição 9 - Maio/2012. Disponível em: www2.marilia.unesp.br/revistas/index.php/levs/article/download/2285/188. Acesso em 13 de Jan. 2018

DI PIERRO, M.C. Trajetória recente da educação de jovens e adultos na América Latina e Caribe.Cadernos de Pesquisa, São Paulo, v. 38, n.134, maio/ago. 2008.

FRANÇA, Marlene Helena de Oliveira. Prisão, Tráfico e Maternidade: um estudo sobre mulheres encarceradas. Tese (doutorado em Sociologia). João Pessoa-PB, UFPB, 2013. Não paginado. Disponível em: http://tede.biblioteca.ufpb.br/bitstream/tede/7302/1/arquivototal.pdf. Acesso em 13 de Jan. 2018.

MARX, Karl. Dezoito de Brumário. São Paulo: Martins Fontes, 2006. 


\section{A DESIGUALDADE DE GÊNERO QUE REFLETE NO ENCARCERAMENTO FEMININO BRASILEIRO}

MOURA, Maria Juruena de. Porta Fechada, Vida Dilacerada - Mulher, tráfico de drogas e prisão: estudo realizado no presídio feminino do Ceará. Dissertação (Mestrado em Políticas Públicas e Sociedade). UECE, $2005 . \quad$ Dortaleza, em: http://www.uece.br/politicasuece/dmdocuments/dissertacao_juruena_moura.pdf. Acesso em: 23 de ago. 2017.

OLIVEIRA, Leandra Salustiana da Silva. Educação prisional: um estudo do processo educativo dos presos do regime semiaberto. Dissertação (Mestrado em Educação). Paranaíba, MS:UEMS, 2014. Disponível em: http://www.uems.br/pgedu/arquivos/1_2014-09-02_09-45-52.pdf. Acesso: 29 de março de 2017.

Artigo submetido em 18/04/2019, e aceito em 26/07/2019. 